\title{
Docosahexaenoic acid monoglyceride induces apoptosis and autophagy in breast cancer cells via lipid peroxidation-mediated endoplasmic reticulum stress
}

\author{
Tian-tian Wang \\ Ningbo University \\ Yong Yang \\ Ningbo University \\ Feng Wang \\ Ningbo University \\ Wen-ge Yang \\ Ningbo University \\ Jin-jie Zhang ( $\square$ zhangjinjie@nbu.edu.cn ) \\ Ningbo University \\ Zu-quan Zou ( $\square$ zouzuquan@nbu.edu.cn ) \\ Ningbo University
}

\section{Research}

Keywords: MAG-DHA, breast cancer, apoptosis, autophagy, lipid peroxidation, endoplasmic reticulum stress

Posted Date: September 8th, 2021

DOI: https://doi.org/10.21203/rs.3.rs-35529/v2

License: (c) (i) This work is licensed under a Creative Commons Attribution 4.0 International License. Read Full License

Version of Record: A version of this preprint was published at Journal of Food Science on September 7th, 2021. See the published version at https://doi.org/10.1111/1750-3841.15900. 


\section{Abstract}

Epidemiologic and pre-clinical studies have shown that marine $n-3$ polyunsaturated fatty acids ( $\mathrm{n}-3$ PUFAs) elicit promising chemoprevention against breast cancer. Docosahexaenoic acid monoglyceride (MAG-DHA), a docosahexaenoic acid sn-1-monoacylglyceroldoes not required pancreatic lipase to be absorbed, eliciting a better bioavailability when compared with other formulations such as DHA-free fatty acid, DHA-triglycerol, or DHA-ethyl ester. However, the anti-cancer actions and underlying mechanisms of MAG-DHA on breast cancer remain to be assessed. In this study, MAG-DHA induced significant growth inhibition in MCF-7 and MDA-MB-231 breast cancer cells in a dose-dependent manner. MAG-DHA treatment $(80 \mu \mathrm{M})$ led to $83.8 \%$ and $94.3 \%$ growth inhibition between MCF-7 and MDA-MB-231 cells, respectively. MAG-DHA-induced growth inhibition was tightly associated with apoptosis, as evidenced by increased active forms of caspase-3, poly (ADP-ribose) polymerase (PARP) and caspase-12. In particular, MAG-DHA-induced apoptosis was triggered by oxidative stress-mediated endoplasmic reticulum (ER) stress, as evidenced by activation of the PERK-elF2a pathway in ER. MAG-DHA treatment also strongly suppressed the growth of E0771 murine breast cancer xenografts, significant differences of tumor volume were found between MAG-DHA group $\left(0.271 \mathrm{~cm}^{3}\right)$ and control group $\left(0.875 \mathrm{~cm}^{3}\right)$ after 15 daily MAG-DHA treatments. The in vitro anti-breast cancer mechanism of MAG-DHA was supported by the in vivo xenograft model. In addition, MAG-DHA-induced ER stress concomitantly triggered autophagy in these cancer cells, and the induction of autophagy suppressed its ability to induce apoptotic cell death. Our data suggested that MAG-DHA as dietary supplement, in combination with autophagy inhibitors may be a useful therapeutic strategy in treating breast cancer.

\section{Introduction}

Breast cancer is by far the most frequently diagnosed cancer among women across the globe, with over 2 million new cases estimated in 2018. It also ranks as the leading cause of cancer-related mortality in females worldwide, leading to over 500,000 deaths per year worldwide (Waks and Winer 2019). Despite recent advances in both diagnosis and treatment, drug resistance and the development of deadly metastases of node-negative or positive breast cancer patients continue to represent a significant clinical challenge (Harbeck and Gnant 2017). Therefore, preventive strategies, novel interventions and therapeutic approaches are urgently needed.

Recently, a large body of literature has indicated that dietary interventions might be able to reduce breast cancer risk (Anjom-Shoae and others 2020; Al-Jawadi and others 2018). Among the dietary factors, n-3 polyunsaturated fatty acids (n-3 PUFAs), especially docosahexaenoic acid (DHA, 22:6, n-3) and eicosapentaenoic acid (EPA, 20:5, n-3), naturally present in cold-water fish as well as in fish oil supplements have gained attention as possible candidates for breast cancer prevention. To date, n-3 PUFA supplements are present in foods as triacylglycerol (TAG) or in small proportions as monoacylglycerol, diacylglycerol (DAG), or phospholipid formulation (James and M. 2015). There is evidence that the influences of the chemical structures on fatty acids bioavailability have been characterized. Studies have shown that MAG-DHA, a DHA sn-1-monoacylglyceroldoes not required 
pancreatic lipase to be absorbed, unlike DHA-triglyceride which needs to behydrolyzed by sn1,3'specificgastric and (colipase-dependent) pancreatic lipases as free fatty acids and monoglycerol prior to intestinal absorption. Therefore, this property confers increased absorption, and thus a better bioavailability when compared with other formulations such as DHA-triglycerol (TAG-DHA), or DHA-ethyl ester (EE-DHA)(Fortin 21 February, 2012; Fortin 17 July, 2012). Cruz-Hernandez et al. demonstrated that an enriched sn-1(3)-MAG oil was a better carrier forn-3 long-chain PUFAs (LC-PUFAs) compared with TAG from fish oil(Cruz-Hernandez and others 2016). It was also found that MAG-DHA induced powerful inflammation resolution in various models of pulmonary diseases (Morin 2015; Khaddaj-Mallat and others 2015). In addition, recent studies have shown that MAG-DHA displayed anti-tumorigenic effects in colorectal cancer and lung cancer (Morin and others 2017; Morin 2013). However, the anti-breast cancer activity of MAG-DHA and its underlying mechanisms remain elusive. The specific objective was to evaluate the effect of MAG-DHA on tumor growth and its underlying molecular mechanisms using an in vitro model of breast cancer cell lineMCF-7 and MDA-MB-231 and an in vivo mouse model of E0771 xenograft.

\section{Materials And Methods}

\subsection{Cell culture and cell viability assay}

The murine E0771 cells were obtained from Roswell Park Cancer Institute (NewYork, USA)\normal breast cell MCF10A, human cancer cell lines MCF-7 (estrogen and progesterone receptors positive ER+/PR+) and MDA-MB-231 (estrogen and progesterone receptors negative ER-/PR-) were obtained from American Type Culture Collection (Manassas, VA, USA). E0771, MCF-7 and MDA-MB-231cells were maintained in RPMI 1640, Dulbecco's Modified Eagle's Medium (DMEM) and L-15 medium Supplemented with 10\% FBS, $2 \mathrm{mM}$ L-glutamine, and penicillin/streptomycin, respectively. MCF10A cells were cultured in DMEM-F12 supplemented with $5 \%$ horse serum, $20 \mathrm{ng} / \mathrm{mL}$ epidermal growth factor, $10 \mathrm{Ag} / \mathrm{mL}$ insulin, and $0.5 \mathrm{Ag} / \mathrm{mL}$ hydrocortisone. For the testing of MAG-DHA (NU-CHEK, USA)on cell viability change, the MTT assay was used. MCF10A, MCF-7 and MDA-MB-231 cells were treated with MAG-DHA complexes to BSA in a 4:1 (MAG-DHA/BSA) molar ratio at 20,40,60,80 and $100 \mu \mathrm{M}$ or vehicle (DMSO) for 24,48 and72 $\mathrm{h}$ in medium containing $0.5 \%$ FBS. MTT reagent (at $5 \mathrm{mg} / \mathrm{ml}$ ) was added to each well at final concentration $0.5 \mathrm{mg} / \mathrm{ml}$ and the plate was incubated at $37^{\circ} \mathrm{C}$. After $4 \mathrm{~h}$, supernatant was carefully removed and DMSO $(100 \mu \mathrm{l})$ was added. The absorbance was read with a microplate reader (Bio-Rad, China) at $450 \mathrm{~nm}$. The relative cell viability was expressed as a percentage of the control well.

\subsection{Lipid peroxidation assay}

The content of MDA in cultured cells or tumor tissues was determined by MDA kit. The tests were performed according to the manufacturer's instructions (Biyotime Biotechnology, Jiangsu, China). Briefly, MCF10A, MCF-7 and MDA-MB-231 cells $\left(1 \times 10^{6}\right)$ were treated with $40 \mu \mathrm{M}$ MAG-DHA alone or in the co- 
presence of $5 \mathrm{mM} \mathrm{NAC}$ for $48 \mathrm{~h}$. Cells were collected and protein concentrations were measured.0.2 ml of $0.091 \%$ thiobarbituric acid (TBA) reagent was added to the cell suspension $(0.1 \mathrm{ml})$, and the samples were heated in boiling water for $20 \mathrm{~min}$. After cooling to room temperature, the samples were centrifuged at $15,000 \mathrm{rpm}$ for $10 \mathrm{~min}$ at $4^{\circ} \mathrm{C}$. The TBA-reactive substances (RS) produced by lipid peroxidation was measured in the supernatant with a microplate reader (Bio-Rad, China) at $532 \mathrm{~nm}$. The results were expressed as MDA $\mu \mathrm{M} / \mathrm{g}$ protein.

\section{Measurements of intracellular ROS}

Intracellular ROS was detected by 2,7-dichlorofluorese in diacetate reagent (DCFH-DA, MCE, China) according to the manufacturer's instructions. Briefly, MCF10A, MCF7 and MDA-MB-231 cells were seeded in confocal Petri dishes, then after treatment, cells were incubated with DCFH-DA $(25 \mu \mathrm{M})$ for $1 \mathrm{~h}$ at $37^{\circ} \mathrm{C}$ and washed three times with PBS. Then, real-time fluorescent of samples was read by microscopy. Image $\mathrm{J}$ software was used for fluorescence signal analysis.

\section{Autophagic flux measurement}

To monitor autophagic flux, MCF7 and MDA-MB-231 cells were transfected with an adenovirus of tandem fluorescent mRFP-GFP-LC3B (a vital marker for autophagosomes and autolysosomes) according to the manufacturer's instructions (Hanheng biology company., Ltd, Shanghai, China). After treatment, cells werewashed and monitored over time for EGFP and m-Cherry under a confocal fluorescence microscope (Leica DM 2500).

\subsection{Tumor xenograft model}

Murine E0771 xenografts were established in 8-week-old female C57/BL6 mice. 20 female C57/BL6 mice at 8 weeks of age were obtained from Shanghai SLAC Experimental Animal CO., Ltd (Shanghai, China) and used according to the approved protocol by the Animal Care and Use Committee of the Ningbo University (Ningbo, China). The mice were housed under aseptic conditions in standard cages in temperature- and humidity-controlled conditions with a $12 \mathrm{~h}$ light/dark cycle. Cultured murine E0771 cells were collected, washed twice with serum-free DMEM and counted. Each mouse received a subcutaneous injection of $2 \times 10^{6}$ viable cells suspended in $100 \mu \mathrm{l}$ of serum-free RPMI 1640 medium on day zero. All injections were given to anesthetized animals. After the formation of $100 \mathrm{~mm}^{3}$ tumors, mice were randomly assigned into 2 groups, control (untreated) and MAG-DHA-treated. Mice were administered by MAG-DHA intragastrically daily at a pharmacological dose of $617 \mathrm{mg} / \mathrm{kg} /$ day corresponding to a daily $\mathrm{n}$ 3 PUFA dose of $3 \mathrm{~g} /$ day for a $60 \mathrm{~kg}$ person, following dose conversion of human to mouse by the equation described by Reagan-Shaw(Reagan-Shaw and others 2007).Tumor size was measured with a caliper every 3 days, and calculated according to the following formula: tumor volume $=$ length $\times$ 
width ${ }^{2} \times 0.5$. Mice were euthanized on week 4 and tumor tissues were removed and stored at $-80^{\circ} \mathrm{C}$ until tissue processing.

\subsection{Transmission electron microscopy (TEM) analysis for cell apoptosis and autophagy}

Tumor tissues were fixed in $4 \%$ paraformaldehyde and post-fixed $2 \%$ osmium tetroxide before embedding in EPON resin for morphological studies. Ultrathin sections (100 nm on 200-mesh grids) embedded in epoxy resin were double stained with uranyl acetate and lead citrate, and observed with Philips CM10 TEM.

\subsection{Tissue and plasma analysis of DHA}

DHA levels of tissues were determined by gas chromatography, as described previously (Bellenger and others 2004). In brief, tissues were homogenized by grinding it in liquid nitrogen. Total lipids of tumor tissues were extracted using the chloroform: methanol mixture $(2: 1, \mathrm{v} / \mathrm{v})$, dried under a stream of nitrogen gas and then transmethylated by heating in $14 \%$ boron trifluoride in methanol at $80^{\circ} \mathrm{C}$ for 20 min. Fatty acid methyl esters were then extracted in presence of $2 \mathrm{ml}$ isooctane and separated by Shimadzu GC-14C gas chromatograph system (Shimadzu Corporation, Japan) equipped with a flame-ionization detector (FID) and a capillary column (DB-23, Aglient Corporation, USA). Fatty acids peaks were identified by their relative retention times comparing with those of commercial fatty acid methyl ester (NU-CHEK, USA). DHA level was expressed as a relative percentage of total analyzed fatty acids according to its peak area.

\subsection{Western blotting analysis}

Tumor tissues were lysed in Triton $x-100$ lysis buffer $(20 \mathrm{mM}$ Tris-HCl, pH7.6, 1 mM EDTA, $140 \mathrm{mM} \mathrm{NaCl}$, $1 \%$ NonidetP-40, $1 \%$ aprotinin, $1 \mathrm{mM}$ phenylmethylsulfonyl fluoride, and $1 \mathrm{mM}$ sodium vanadate). Lysates were sonicated and centrifuged at $15000 \mathrm{~g}$ for 10 minutes at $4{ }^{\circ} \mathrm{C}$. Protein concentrations were determined using bicinchoninic acid (BCA) protein assay kit purchased from Biyuntian Biotech (Haimen, China). Supernatants were separated on 10\% SDS-PAGE and transferred to nitrocellulose membranes. Membranes were blocked in milk and incubated at $4{ }^{\circ}$ Covernight with primary antibodies followed by incubation with secondary antibodies for $1 \mathrm{~h}$ at room temperature. Detection was performed by enhanced chemiluminescence. The primary antibodies rabbit anti-NF-E2-related factor 2 (Nrf2), rabbit anti-Heme Oxygenase 1(HO-1), rabbit anti-protein kinase R-like ER kinase (PERK), rabbit anti-phospho (p)-PERK (Thr980), rabbit anti-phospho (p)-eiF2a (Ser51), rabbit anti-eiF2a, rabbit anti-C/EBP homologous protein $\triangle \mathrm{CHOP}$, rabbit anti-cleaved caspase-12, rabbit anti-caspase-12, rabbit anti-cleaved caspase-3, rabbit anticaspase-3, rabbit anti-cleaved PARP,rabbit anti-PARP, rabbit anti-LC3BI/II, rabbit anti-p62, rabbit anti- 
Beclin-1, mouse anti- $\beta$-actin and the horseradish peroxidase-linked secondary antibodies were purchased from Cell Signaling Technology (Danvers, MA, USA).

\subsection{Transfection of siRNAs}

To study the role of Beclin-1 in MAG-DHA-induced growth inhibition of breast cancer cells, Beclin 1 specific siRNAs and the control siRNAs were transiently transfected to MCF-7 and MDA-MB-231cells using Dharma-FECT-1 (DBA Dharmacon, Lafayette, CO), according to manufacturers' recommendation. The target sequences for Beclin-1-specific siRNAs were 5'-UGGAAUGGAAUGAGAUUAATT-3' and 5'GCUCAGUAUCAGAGAGAAUTT-3' (GeneBank accession number NM003766.2). The efficacy of the siRNA knockdown of Beclin-1 protein expression was determined by western blotting analysis.

\subsection{Statistical analysis}

The results were presented as the mean \pm SEM and statistical differences were evaluated byone-way ANOVA followed by Newman-Keuls test. $P<0.05$ was considered to indicate statistical significance.

\section{Results}

\subsection{MAG-DHA induced lipid peroxidation-mediated endoplasmic reticulum (ER) stress in cultured breast cancer cells}

First, we examined the effects of MAG-DHA on proliferation of human normal breast cell MCF10A, human breast cancer cell MCF-7 and MDA-MB-231. Cell viability assays were performed after 24, 48 and $72 \mathrm{~h}$ of treatment of MAG-DHA at increasing concentrations of 20,40,60, 80 and $100 \mu \mathrm{M}$. MCF10A cells were not sensitive to MAG-DHA treatment, cell viability was $87 \%$ upon treatment of $80 \mu M$ MAG-DHA for $72 \mathrm{~h}$ (Fig.1A, Supplementary Fig. 1). However, MAG-DHA was found to significantly reduced the viability (based on MTT assay) of MCF-7 and MDA-MB-231 cells in a concentration and time-dependent manner (Fig.1A, Supplementary Fig. 1). Compared with MCF-7 cells, MDA-MB-231 cells were more sensitive to MAG-DHA (Fig. 1A). Cell viability rate of MDA-MB-231 was $5.7 \%$, compared with $16.2 \%$ in MCF-7 cells upon treatment of $80 \mu \mathrm{M}$ MAG-DHA for $72 \mathrm{~h}$ (Fig. 1A). The IC50 of MAG-DHA treatment was $5.4 \mu \mathrm{M}$, and $29.3 \mu \mathrm{M}$ in MDA-MB-231 and MCF-7 cells for $72 \mathrm{~h}$, respectively. The IC50 of MAG-DHA treatment was $68.6 \mu \mathrm{M}(24 \mathrm{~h}), 33.1 \mu \mathrm{M}(48 \mathrm{~h})$ and $83.2 \mu \mathrm{M}(24 \mathrm{~h}), 67.2 \mu \mathrm{M}(48 \mathrm{~h})$ in MDA-MB-231 and MCF-7 cells, respectively. It was worth noting that the anti-proliferative effects of MAG-DHA in both breast cancer cells were significantly counteracted by N-acetyl-L-cysteine (NAC), a well-known antioxidant. Upon treatment of $80 \mu \mathrm{M}$ MAG-DHA for $72 \mathrm{~h}$ in the presence of NAC, cell viability rate reached to $69.7 \%$ and $82.1 \%$ in MDAMB-231 and MCF-7, respectively (Fig. 1A, Supplementary Fig. 1).Since the unsaturated nature of MAGDHA with 6 double bonds renders its structure more prone to free radicals by triggering lipid peroxidation, we therefore focused on examining intracellular ROS and lipid peroxidation to investigate the cellular 
mechanism by which MAG-DHA induced anti-proliferative actions in cultured cells. As shown in Fig. 1B\&C, MAG-DHA treatment significantly increased ROS production in MCF-7 and MDA-MB-231 cells, but not in MCF10A cells, ROS levels increased 9 fold and 10 fold in MCF-7 and MDA-MB-231 cells, respectively. NAC could markedly suppress ROS production induced by MAG-DHA. Similarly, MAG-DHA treatment also significantly increased MDA levels in MCF-7 and MDA-MB-231 cells, but not in MCF10A cells (Fig. 1D). MDA levels increased from 0.32 and $0.29 \mu \mathrm{mol} / \mathrm{g}$ to 3.77 and $3.45 \mu \mathrm{mol} / \mathrm{g}$ in MCF-7 and MDA-MB-231 cells, respectively. Co-treatment of cells with NAC and MAG-DHA markedly suppressed intracellular MDA accumulation, MDA levels decreased to 0.52 and $0.34 \mu \mathrm{mol} / \mathrm{g}$ in MCF-7 and MDA-MB231 cells, respectively. Next, we determine whether MAG-DHA-induced lipid peroxidation could activate the antioxidant defense system. As shown in Fig. 1E\&F, Nrf2 and HO-1, two crucial components of cellular oxidative stress response were significantly up-regulated in MCF-7 and MDA-MB-231 cells treated with MAG-DHA. These results suggest the antioxidant defense system was activated in response to MAG-DHAmediated lipid peroxidation. In addition, Co-treatment of cells with NAC and MAG-DHA also markedly inactivated the antioxidant defense system (Fig.1E\&F). It is widely accepted that oxidative stress is linked with ER stress (Bhandary and others 2012), we therefore wondered whether MAG-DHA-induced lipid peroxidation led to ER stress. As expected, we found that the protein levels of phosphorylated PERK, a major transducer of ER stress and phosphorylated eiF2a, a downstream target of PERK were significantly increased in MCF-7 and MDA-MB-231 cells treated with MAG-DHA, although the total amount of PERK and eiF2a did not change (Fig. 2A\&B). Simultaneously, we also found that CHOP, an ER stress-inducible transcription factors associated with cell cycle arrest and apoptosis was significantly up-regulated in MCF-7 and MDA-MB-231 cells treated with MAG-DHA (Fig. 2A\&B). Co-treatment of cell with NAC markedly reversed lipid peroxidation-induced ER-stress (Fig. 2A\&B). In addition, the involvement of ER stress in MAG-DHA-induced growth inhibition was further confirmed in both cells co-treated with 4-PBA, an ER stress inhibitor and MAG-DHA. As shown in Fig. 2C, MAG-DHA-induced growth inhibition was significantly counteracted by 4-PBA in both cells. Cell viability rate increased from $35.2 \%$ and $12.7 \%$ to $79.0 \%$ and

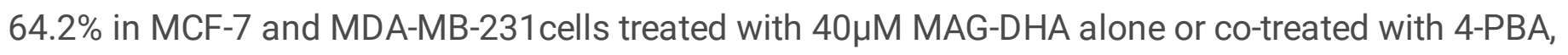
respectively.

\subsection{MAG-DHA-induced ER stress resulted in cell apoptosis and autophagy in cultured breast cancer cells}

Next, in order to investigated whether MAG-DHA-induced ER stress triggered apoptosis induction, we evaluated the typical hallmarks of cells undergoing apoptosis in both breast cancer cells treated with MAG-DHA. We found that the active forms (cleaved forms) of caspase-12, a apoptosis protein specifically activated upon ER stress, cleaved caspase-3 and poly (ADP-ribose) polymerase (PARP), two key mediators of apoptosis were significantly increased in both cells treated with MGA-DHA, and co-treatment of cells with 4-PBA prevented MAG-DHA-induced apoptosis pathway activation(Fig. 2D\&E). In addition, MAG-DHA treatment significantly induced cell morphology changes in MCF-7 and MDA-MB-231 cells, and Co-treatment of cells with NAC markedly reversed this process (Supplementary Fig. 2). Evidence is accumulating that interesting functional links exists between ER stress and autophagy (Ogata and others

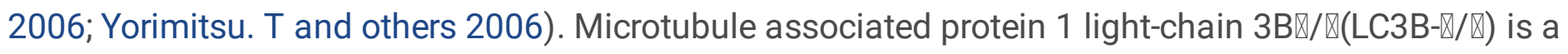
specific membrane marker for the detection of early autophagosome formation, and p62/SQSTM1 is 
degraded upon autophagy induction.Beclin-1, the first mammalian autophagy protein, plays a key role in autophagy initiation. To determine whether MAG-DHA-induced ER stress also activated autophagy, the

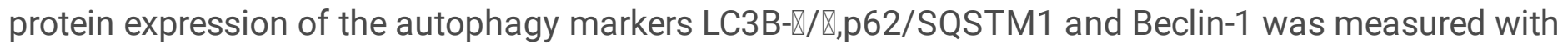
immunoblotting analyses. As shown in Fig. 3A\&B, immunoblotting analyses demonstrated

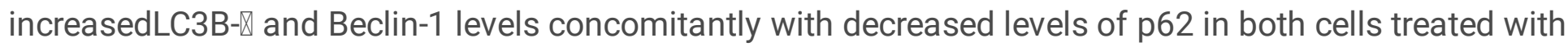
MAG-DHA. Simultaneously, MAG-DHA-induced autophagy was prevented by co-treatment of cells with 4PBA. In addition, we also investigated the effect of autophagy in MAG-DHA-mediated growth inhibition using Beclin-1 specific siRNAs (Fig. 3C). Genetic silencing of Beclin-1 expression (siBeclin-1 1 and siBeclin-1 2) induced slight growth inhibition of $4.13 \%$ and $8.74 \%$ in MCF-7 cells, respectively. Similarly, siBeclin-1 1 and siBeclin-1 2 induced growth inhibition of $6.87 \%$ and $6.04 \%$ in MDA-MB-231 cells, respectively (Fig. 3D). Importantly, cell growth inhibition increased from $34.0 \%$ to $56.7 \%$ and $63.0 \%$ in MCF-7 cells co-treated with $40 \mu \mathrm{M}$ MAG-DHA and siBeclin-1 1 or siBeclin-12, respectively. Simultaneously, it was also observed that growth inhibition increased from $48.3 \%$ to $79.0 \%$ and $87.4 \%$ in MDA-MB-231 cells co-treated with $40 \mu \mathrm{M}$ MAG-DHA and siBeclin-1 1 or siBeclin-1 2, respectively (Fig. 3D). Finally, we investigated the effect of autophagy in MAG-DHA-mediated growth inhibition using autophagy inhibitor chloroquine (CQ). As shown in Fig. 3E, CQ induced 8.5\% and 5.2\% growth inhibition in MCF-7 and MDAMB-231 cells, respectively. Co-treatment with MAG-DHA and CQ induced growth inhibition $(59.7 \%$ and 79.5\%), compared with growth inhibition (38.0\% and 51.4\%) in MCF-7 and MDA-MB-231 cells treated with MAG-DHA alone, respectively (Fig. 3E), suggesting pharmacologic inhibition of autophagy by CQ enhanced MAG-DHA-induced growth inhibition. In addition, in order to determine the fusion efficiency of autophagosome with lysosome, a pH-sensitive, double tagged mCherry-GFP-LC3B reporter which gives rise to yellow fluorescence in autophagosomes and turns red in acidic autolysosomes because of eGFP quenching was used. As shown in Fig. 3F\&G, accumulated autolysosomes (red fluorescence) and few autophagosomes (yellow fluorescence) were observed with MAG-DHA treatment in MCF-7 and MDA-MB231 cells. Co-treatment of cells with CQ induced accumulated autophagosomes in both cells. Our data showed that suggesting that MAG-DHA may be involved in regulating autophagy initiation and promoting autophagic flux process. These results demonstrated that ER stress-triggered autophagy suppressed MAG-DHA-induced apoptotic cell death.

\subsection{MAG-DHAinhibitedthe growth of E0771xenografts}

To evaluate the in vivo anti-proliferative efficacy of MAG-DHA on breast cancer, we implanted

murine E0771 breast cancer cells into mice and examined the tumorigenicity of inoculated tumor cells. As shown in Fig. $4 \mathrm{~B}$, at day 11 , the mean tumor volume is $0.086 \pm 0.017 \mathrm{~cm}^{3}$. Significant differences of tumor volume were found between MAG-DHA group $\left(0.271 \pm 0.059 \mathrm{~cm}^{3}\right)$ and control group $\left(0.875 \pm 0.125 \mathrm{~cm}^{3}\right)$ after 15 daily MAG-DHA treatments. Representative macroscopic images showed MAG-DHAtreatment significantly suppressed tumor growth and reduced the size of tumor xenografts in MAG-DHA-treated group compared to control group (Fig. 4A).

\subsection{The in vitro anti-breast cancer mechanism was supported by the in vivo xenograft model}


To determine whether the mechanism of MAG-DHA-induced cell death observed in vitro also can be seen in vivo, we evaluated the typical hallmarks of cells undergoing apoptosis in tumor tissues with immunoblotting analyses. As shown in Fig. 5A, we found that cleaved caspase-12,cleaved caspase-3 and cleaved PARP were significantly increased in tumor tissues in MAG-DHA group compared with control group. We further evaluated the ultrastructure changes of breast cancer cells from tumor tissues with transmission electron microscopy (TEM). As shown in Fig. 5B, chromatin marginalization, one of classical morphological characteristics of apoptosis was observed in tumor tissues from MAG-DHA

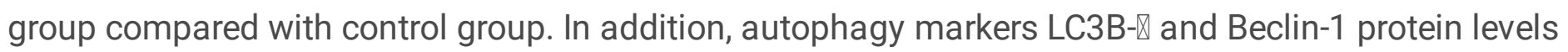
were significantly enhanced,whereas p62 expression was significantly suppressed in MAG-DHA group (Fig. 5C). The induction of autophagy by MAG-DHA treatment was confirmed by TEM analysis, as evidenced by substantial accumulation of autophagosomes with cytoplasmic organelles and other vesicles encapsulated in vacuoles in tumor tissues of MAG-DHA group (Figure. 5D). Next, Analysis of the total lipids extracted from plasma, tumor, liver and muscle tissues showed DHA was significantly elevated in these serum and tissue samples. The DHA level was $4.11 \pm 0.67 \%$ in tumor tissues from MAGDHA group compared with control group $(0.82 \pm 0.19 \%)$ (Fig.6A). Also, increased MDA accumulation was observed in tumor tissues from MAG-DHA group $(0.86 \pm 0.13 \mu \mathrm{mol} / \mathrm{g})$ compared with control group $(0.17 \pm 0.02 \mu \mathrm{mol} / \mathrm{g})$ (Fig. 6B), which activated the antioxidant defense system (Fig.6C). Furthermore, MAGDHA-induced lipid peroxidation led to ER stress in MAG-DHA group, as evidenced by increased expression of phospo-PERK, phospo-eiF2aand CHOP (Fig. 6D). Our data demonstrated that the proposed anticancer mechanisms of MAG-DHA based on in vitro cell model are confirmed by in vivo studies.

\section{Discussion}

Although most dietary lipids in foods were constituted of TAGs, however, TAGs are required to be hydrolyzed into free fatty acids and sn-2- MAG by lipolytic enzymes, mainly sn-1,3 specific pancreatic lipases in the upper part of the gastrointestinal tract in the digest process(Yen and Farese 2003), whereas MAGs are lipase independent and considered as being in a predigested form. Recent studies have found that MAG containing EPA/DHA exhibits a high degree of efficient absorption, especially under impaired absorption conditions compared to conventional dietary TAG (Caroline and others 2018; Cuenoud and others 2020). Therefore, n-3 PUFA in the MAG predigested form may offer a clinical advantage to patients struggling with lipid malabsorption/maldigestion problems. MAG is classified as non-ionic surfactants due to its composition and accounts for about $75 \%$ of the world production of emulsifiers and stabilizers for food purposes (Ferreira-Dias and others 2001). In addition, MAG containing n-3 PUFAs is expected to have variety of application possibilities, such as incorporation into functional foods and dietary supplements, or as ingredients in pharmaceuticals, enzymatic catalysis has been used to produce purer, less degraded n-3 PUFA MAG to meet increasing market demand due to its mild reaction conditions compared to conventional chemical processes in food industry (Bornscheuer 1995). In the present study, MAG-DHA was used to study the anti-breast cancer activity and its underlying mechanisms. It was found that MAG-DHA induced lipid peroxidation-mediated ER stress, which triggered apoptosis and autophagy in cultured MCF7 and MDA-MB-231 breast cancer cells as well as in E0771 xenografts. Notably, MAG- 
DHA-induced autophagy suppressed its ability to induce apoptotic cell death. In addition, we also evaluated the cytotoxicity of MGA-DHA to human normal liver cell L-O2 and rat

pheochromocytoma cell line PC-12. It was found that MAG-DHA slightly promoted the growth of L-02 and PC-12 in medium with 10\% FBS (Supplementary Fig. 3), suggesting that MAG-DHA is not hepatotoxic and neurotoxic, and safe as dietary supplement for prevention of breast cancer.

In E0771xenografts, it is of interest to note that DHA level was increased approximately 4.5 fold with MAG-DHA intervention (Fig. 6A). It is known that the enrichment of DHA with high unsaturation in membranes makes cancer cells more sensitive to free radicals because it makes the membrane less rigid and more vulnerable (Hishikawa and others 2017). Therefore, in the present study, the cell death induced by MAG-DHA was largely mediated by increased lipid peroxidation in cancer cells. The crucial role of lipid peroxidation in MAG-DHA-induced death of breast cancer cells was supported by the following observations: (1) Increased intracellular MDA accumulation in cultured breast cancer cells and in tumor samples in MAG-DHA group, respectively. In addition, MAG-DHA-induced lipid peroxidation also activated antioxidant defense system as evidenced by increased expression of Nrf2 and HO-1, two crucial components of cellular anti-oxidative stress response (Loboda and others 2016). (2) The cell cytotoxicity, increased MDA levels and up-regulated expressions of Nrf2 and HO-1 induced by MAG-DHA in breast cancer cells were effectively reversed by the antioxidant NAC (Fig. 1A-D). In agreement, Jing et al. demonstrated that DHA-induced cell death of breast cancer cells is associated with increased reactive oxygen species, which activates Nrf2/HO-1 signaling pathway (Tsai and others 2017). Also, van Beelen et al. reported that the hydrolysed algal oil and fish oil showed similar toxicity on colon cancer cells via oxidative stress(Beelen and others 2007).

Oxidized lipids was found to trigger ER stress in rat aortic smooth muscle cells (Haberzettl and Hill 2013). PERK, a three transmembrane protein induced the unfolded protein response upon ER stress. Activated PERK phosphorylateseiF2a, which results in repression of global protein synthesis to restore cell homeostasis. However, elevated levels of phosphorylated eif2aalso lead to increased translation of selected mRNAs including the transcription factor ATF4, which promotes expression of CHOP, a transcription factor involved in cell apoptosis (Cao and Kaufman 2014). In the present study, in MAGDHA-treated breast cancer cells or in tumor tissues from MGA-DHA group, we found significant increases in PERK and elF2a phosphorylation levels as well as changes in CHOP expression. Furthermore, the use of antioxidant NAC significantly reversed MAG-DHA-induced ER stress in two breast cancer cells, suggesting that MAG-DHA-induced lipid peroxidation results in ER stress in breast cancer cells. In line with our results, Jakobsen et al. found that DHA induced cell cycle arrest by ER stress in human colon cancer SW620 cells(Jakobsen and others 2008). Similarly, Pettersen et al. also reported that DHA triggered oxidative-stress-mediated ER stress in human colon cancer SW620 cells (Pettersen and others 2016). However, several in vitro and in vivo studies reported that DHA provides neuroprotection against ER stress(Begum and others 2012; Begum and others 2014). This discrepancy may largely be explained by the cell-specific differences in ER stress response. Taken together, the results of the present study suggest that lipid peroxidation-induced ER stress is involved in the anti-breast cancer effects of MAGDHA. 
Many studies have reported that n-3 PUFAs induced apoptosis by triggering the intrinsic mitochondrial and ER pathways(Fukui and others 2013; Liu and Ma 2014). In the present study, by using western blotting and TEM assay, we confirmed that MAG-DHA induced apoptosis in the in vivo tumor xenografts. It has been reported that ER stress has been found to activate caspase-3 apoptotic signaling via caspase12 (Faitova and others 2006).Our results showed that increased expression of active form of caspase-12, caspase-3 and PARP was also observed in MAG-DHA-treated breast cancer cells as well as in tumor tissues from MAG-DHA group, and the use of 4-PBA protected the cells from MAG-DHA-induced cell death, further confirming the involvement of ER stress in MAG-DHA-induced apoptotic cell death. It is speculated that MAG-DHA may preferentially increase ROS in or near the plasma membrane lipid rafts, and trigger lipid peroxidation-mediated ER stress, which leads to cell apoptosis. At the same time, we could not exclude the involvement of mitochondrial pathway in MAG-DHA-induced apoptosis. In line with our results, Connolly et al. reported that dietary DHA, the sole n-3 PUFA found in golden algae oil, depressed the growth of mammary carcinoma in athymic mice through apoptosis induction(Connolly and others 1999).

Autophagy is known as a catabolic process that removes damaged cellular components to maintain cellular integrity and stability under certain conditions, such as in response to nutrient deprivation, organelle damage, or other stresses (Glick and others 2010). However, excessive or prolonged autophagy may also induce cell death (Platini and others 2010). In this study, we found that MAG-DHA not only induced apoptosis but also induces autophagy as evidenced by increased autophagosome formation in the in vivo tumor xenografts. In line with our results, n-3 PUFAs have been found to induce cell autophagy in human pancreatic cancer cells, human multiple myeloma cells and breast cancer cells (Chen and others 2014; Eliseo and others 2017; Fukui and others 2013; Niso-Santano and others 2015).In addition, recent investigations have revealed that ER stress can either stimulate or inhibit autophagy (Rashid and others 2015; Senft and Ronai 2015). In this study, it was found that MAG-DHA-induced ER stress triggered autophagy and protected breast cancer cells from MAG-induced apoptotic cell death, suggesting that a combination of MAG-DHA with autophagy inhibitor may provide a useful strategy in increasing the therapeutic efficacy in breast cancer.

\section{Conclusion}

As summarized in Fig. 7, our results demonstrated that MAG-DHA exerted its anti-proliferative effects in cultured breast cancer cells and in in vivo tumor xenografts. The prevention of MAG-DHA against breast cancer was strongly associated with lipid peroxidation-mediated ER stress, which induced cell apoptosis and autophagy. Whereas MAG-DHA induced autophagy activation suppressed apoptotic cell death. Our study also emphasizes the ongoing need for additional preclinical studies investigating the molecular targets of MAG-DHA in breast cancer cells as well as the urgent need for new clinical studies evaluating the potential role of dietary MAG-DHA supplementation mainly in combination with autophagy inhibitors, chemo-and radio-therapeutic anticancer regimens to improve clinical outcome and survival of breast cancer patients. 


\section{Declarations}

Acknowledgements

This work was supported by National Key R\&D Program of China (grant no.2018YFD0901105, 2020YFD0900900), and partly sponsored by the Fang Runhua Fund of Hong Kong, the K.C. Wong Magna Fund of Ningbo University, Zhejiang Key Laboratory of Pathophysiology (grant no.201802), the Natural Science Foundation of Zhejiang (grant no.LY19H030001), the Ningbo Civil Natural Science Foundation of China (grant no.2018A610377, 2018A610370 and 2019A610253), and the Medical Science and Technology of Zhejiang Province (grant no.2018KY726).

\section{Competing interests}

All authors declare no competing interest.

\section{Authors' contributions}

All authors read and approved the final manuscript. Zu-quan Zou, Jin-jie Zhang and Wen-ge Yang designed overall research experiments. Tian-tian Wang, Yong Yang and Feng Wang performed the experiments and data analysis. Yong Yang collected and analyzed references. Tian-tian Wang wrote the manuscript. All authors read and approved the manuscript.

\section{References}

Al-Jawadi A, Moussa H, Ramalingam L, Dharmawardhane S, Gollahon L, Gunaratne P, Layeequr Rahman R, Moustaid-Moussa N. 2018. Protective properties of n-3 fatty acids and implications in obesityassociated breast cancer. The Journal of nutritional biochemistry 53:1-8.

Anjom-Shoae J, Sadeghi O, Larijani B, Esmaillzadeh A. 2020. Dietary intake and serum levels of trans fatty acids and risk of breast cancer: A systematic review and dose-response meta-analysis of prospective studies. Clinical nutrition 39(3):755-64.

Beelen VAV, Roeleveld J, Mooibroek H, Sijtsma L, Bino RJ, Bosch D, Rietjens IMCM, Alink GM. 2007. A comparative study on the effect of algal and fish oil on viability and cell proliferation of Caco-2 cells. Food \& Chemical Toxicology 45(5):716-24.

Begum G, Kintner D, Liu Y, Cramer SW, Sun D. 2012. DHA inhibits ER Ca2+ release and ER stress in astrocytes following in vitro ischemia. Journal of neurochemistry 120(4):622-30.

Begum G, Yan HQ, Li L, Singh A, Dixon CE, Sun D. 2014. Docosahexaenoic acid reduces ER stress and abnormal protein accumulation and improves neuronal function following traumatic brain injury. The Journal of neuroscience : the official journal of the Society for Neuroscience 34(10):3743-55. 
Bellenger J, Bellenger S, Clément L, Mandard S, Diot C, Poisson JP, Narce M. 2004. A new hypotensive polyunsaturated fatty acid dietary combination regulates oleic acid accumulation by suppression of stearoyl CoA desaturase 1 gene expression in the SHR model of genetic hypertension. Faseb Journal Official Publication of the Federation of American Societies for Experimental Biology 18(6):773-5.

Bhandary B, Marahatta A, Kim HR, Chae HJ. 2012. An involvement of oxidative stress in endoplasmic reticulum stress and its associated diseases. Int J Mol Sci 14(1):434-56.

Bornscheuer UT. 1995. Lipase-catalyzed syntheses of monoacylglycerols. Enzyme \& Microbial Technology 17(7):578-86.

Cao SS, Kaufman RJ. 2014. Endoplasmic reticulum stress and oxidative stress in cell fate decision and human disease. Antioxidants \& redox signaling 21(3):396-413.

Caroline M, André C, Félix-Antoine V, Samuel F. 2018. The Efficacy of MAG-DHA for Correcting AA/DHA Imbalance of Cystic Fibrosis Patients. Marine Drugs 16(6):184-.

Chen Z, Zhang Y, Jia C, Wang Y, Lai P, Zhou X, Wang Y, Song Q, Lin J, Ren Z, Gao Q, Zhao Z, Zheng H, Wan Z, Gao T, Zhao A, Dai Y, Bai X. 2014. mTORC1/2 targeted by n-3 polyunsaturated fatty acids in the prevention of mammary tumorigenesis and tumor progression. Oncogene 33(37):4548-57.

Connolly JM, Gilhooly EM, Rose DP. 1999. Effects of reduced dietary linoleic acid intake, alone or combined with an algal source of docosahexaenoic acid, on MDA-MB-231 breast cancer cell growth and apoptosis in nude mice. Nutrition and cancer 35(1):44-9.

Cruz-Hernandez C, Destaillats F, Thakkar SK, Goulet L, Wynn E, Grathwohl D, Roessle C, de Giorgi S, Tappy L, Giuffrida F, Giusti V. 2016. Monoacylglycerol-enriched oil increases EPA/DHA delivery to circulatory system in humans with induced lipid malabsorption conditions. Journal of lipid research 57(12):2208-16.

Cuenoud B, Rochat I, Gosoniu ML, Dupuis L, Berk E, Jaudszus A, Mainz JG, Hafen G, Beaumont M, CruzHernandez C. 2020. Monoacylglycerol Form of Omega-3s Improves Its Bioavailability in Humans Compared to Other Forms. Nutrients 12(4).

Eliseo DD, Renzo LD, Santoni A, Velotti F. 2017. Docosahexaenoic acid (DHA) promotes immunogenic apoptosis in human multiple myeloma cells, induces autophagy and inhibits STAT3 in both tumor and dendritic cells. Genes \& Cancer 8(1-2):12.

Faitova J, Krekac D, Hrstka R, Vojtesek B. 2006. Endoplasmic reticulum stress and apoptosis. Cellular \& molecular biology letters 11(4):488-505.

Ferreira-Dias S, Correia AC, Baptista FO, Fonseca MMRD. 2001. Contribution of response surface design to the development of glycerolysis systems catalyzed by commercial immobilized lipases. Journal of Molecular Catalysis B Enzymatic 11(4-6):699-711. 
Fortin S. 17 July, 2012. Compositions Comprising Polyunsaturated Fatty Acid Monoglycerides or Derivatives Thereof andUses Thereof. U.S. Patent 8, 222,295 B2.

Fortin S. 21 February, 2012. Polyunsaturated Fatty Acid Monoglycerides, Derivatives, and Uses Thereof. U.S. Patent 8, 119, 690 B2.

Fukui M, Kang KS, Okada K, Zhu BT. 2013. EPA, an omega-3 fatty acid, induces apoptosis in human pancreatic cancer cells: Role of ROS accumulation, caspase-8 activation, and autophagy induction. Journal of Cellular Biochemistry 114(1):192-203.

Glick D, Barth S, Macleod KF. 2010. Autophagy: cellular and molecular mechanisms. The Journal of Pathology 221(1):3-12.

Haberzettl P, Hill BG. 2013. Oxidized lipids activate autophagy in a JNK-dependent manner by stimulating the endoplasmic reticulum stress response. Redox Biology 1(1):56-64.

Harbeck N, Gnant M. 2017. Breast cancer. The Lancet 389(10074):1134-50.

Hishikawa D, Valentine WJ, lizuka-Hishikawa Y, Shindou H, Shimizu T. 2017. Metabolism and functions of docosahexaenoic acid-containing membrane glycerophospholipids. FEBS letters 591(18):2730-44.

Jakobsen CH, Storvold GL, Bremseth H, Follestad T, Sand K, Mack M, Olsen KS, Lundemo AG, Iversen JG, Krokan HE, Schonberg SA. 2008. DHA induces ER stress and growth arrest in human colon cancer cells: associations with cholesterol and calcium homeostasis. Journal of lipid research 49(10):2089-100.

James MJ, Spargo, L.D., Metcalf, R.G., Sullivan, T.R., Rischmueller, M. F, K., Wechalekar, M.D., Lee, A.T., Cleland, L. G. 2015. Fish oil in recent onset rheumatoid arthritis: a randomised, double-blind controlled trial within algorithm-based drug use. Annals of the rheumatic diseases 74(1):89-95.

Khaddaj-Mallat R, Sirois C, Sirois M, Rizcallah E, Morin C, Rousseau E. 2015. Reversal of IL-13-induced inflammation and $\mathrm{Ca}(2+)$ sensitivity by resolvin and MAG-DHA in association with ASA in human bronchi. Prostaglandins \& other lipid mediators 121(Pt B):145-54.

Liu J, Ma DW. 2014. The role of n-3 polyunsaturated fatty acids in the prevention and treatment of breast cancer. Nutrients 6(11):5184-223.

Loboda A, Damulewicz M, Pyza E, Jozkowicz A, Dulak J. 2016. Role of Nrf2/HO-1 system in development, oxidative stress response and diseases: an evolutionarily conserved mechanism. Cellular and molecular life sciences: CMLS 73(17):3221-47.

Morin C. 2013. Anti-Cancer Effects of a New Docosahexaenoic Acid Monoacylglyceride in Lung Adenocarcinoma. Recent Patents on Anti Cancer Drug Discovery 8(3):-. 
Morin C, Cantin, A. M., Rousseau, É., Sirois, M., Sirois, C., Rizcallah, E., Fortin, S. 2015. Pro-resolving Action of MAG-DHA in Lung Inflammatory Models Related to Cystic Fibrosis. American Journal of Respiratory Cell \& Molecular Biology 53(4):574-83.

Morin C, Rodriguez E, Blier PU, Fortin S. 2017. Potential Application of Eicosapentaenoic Acid Monoacylglyceride in the Management of Colorectal Cancer. Mar Drugs 15(9).

Niso-Santano M, Malik SA, Pietrocola F, Bravo-San Pedro JM, Marino G, Cianfanelli V, Ben-Younes A, Troncoso R, Markaki M, Sica V, Izzo V, Chaba K, Bauvy C, Dupont N, Kepp O, Rockenfeller P, Wolinski H, Madeo F, Lavandero S, Codogno P, Harper F, Pierron G, Tavernarakis N, Cecconi F, Maiuri MC, Galluzzi L, Kroemer G. 2015. Unsaturated fatty acids induce non-canonical autophagy. The EMBO journal 34(8):1025-41.

Ogata M, Hino S, Saito A, Morikawa K, Kondo S, Kanemoto S, Murakami T, Taniguchi M, Tanii I, Yoshinaga K, Shiosaka S, Hammarback JA, Urano F, Imaizumi K. 2006. Autophagy is activated for cell survival after endoplasmic reticulum stress. Molecular and cellular biology 26(24):9220-31.

Pettersen K, Monsen VT, Hakvag Pettersen CH, Overland HB, Pettersen G, Samdal H, Tesfahun AN, Lundemo AG, Bjorkoy G, Schonberg SA. 2016. DHA-induced stress response in human colon cancer cells Focus on oxidative stress and autophagy. Free radical biology \& medicine 90:158-72.

Platini F, Pérez-Tomás R, Ambrosio S, Tessitore L. 2010. Understanding Autophagy in Cell Death Control.pdf. Current Pharmaceutical Design 16:14.

Rashid H-O, Yadav RK, Kim H-R, Chae H-J. 2015. ER stress: Autophagy induction, inhibition and selection. Autophagy 11(11):1956-77.

Reagan-Shaw S, Nihal M, Ahmad N. 2007. Dose translation from animal to human studies revisited. The FASEB Journal 22(3):659-61.

Senft D, Ronai ZA. 2015. UPR, autophagy, and mitochondria crosstalk underlies the ER stress response. Trends in biochemical sciences 40(3):141-8.

Tsai C-H, Shen Y-C, Chen H-W, Liu K-L, Chang J-W, Chen P-Y, Lin C-Y, Yao H-T, Li C-C. 2017. Docosahexaenoic acid increases the expression of oxidative stress-induced growth inhibitor 1 through the PI3K/Akt/Nrf2 signaling pathway in breast cancer cells. Food and Chemical Toxicology 108:276-88.

Waks AG, Winer EP. 2019. Breast Cancer Treatment: A Review. JAMA 321(3):288-300.

Yen CLE, Farese RV. 2003. MGAT2, a monoacylglycerol acyltransferase expressed in the small intestine. Journal of Biological Chemistry 278(20):18532-7.

Yorimitsu. T, Nair. U, Yang ZF, Klionsky DJ. 2006. Endoplasmic reticulum stress triggers autophagy. J Biol Chem. 281. 


\section{Figures}

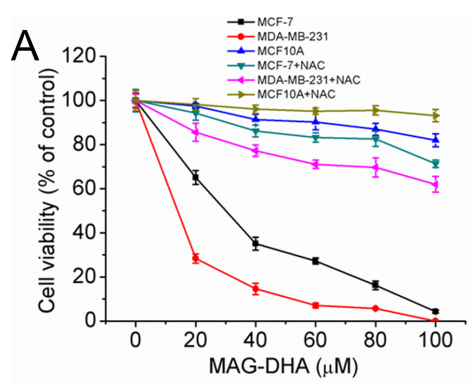

B

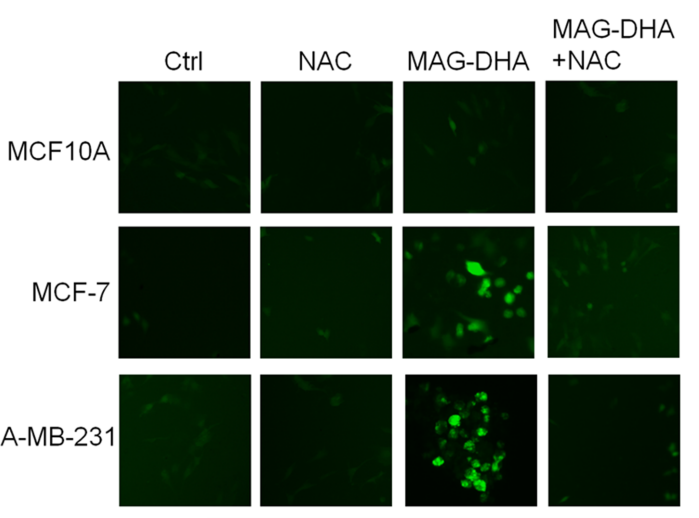

C

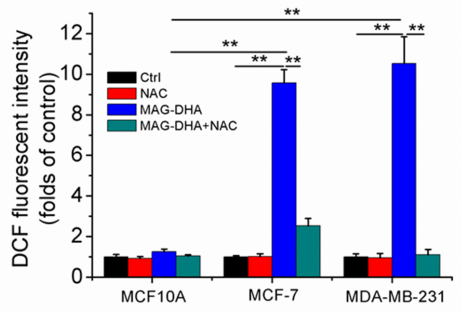

D
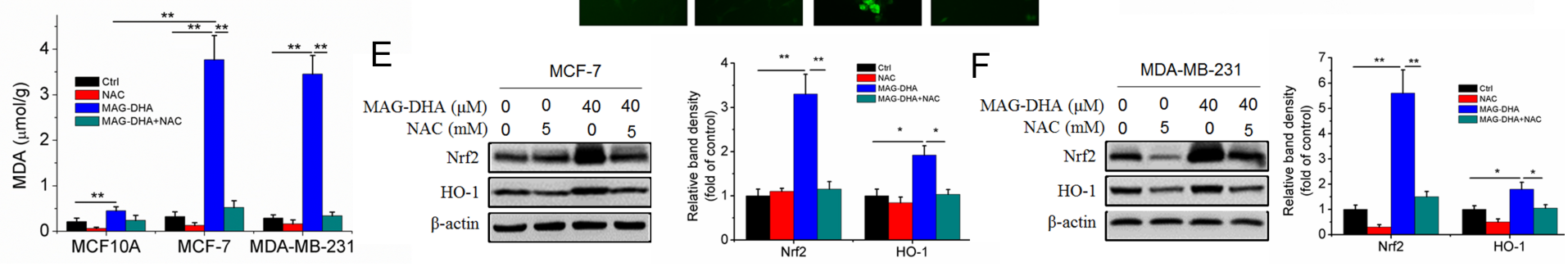

Figure 1

MAG-DHA-induced apoptotic cell death was associated with lipid peroxidation. (A) MCF10A, MCF-7 and MDA-MB-231 cells were treated with MAG-DHA in indicated concentrations alone or in the co-presence of $5 \mathrm{mMN}$-acetyl-L-cysteine (NAC) for $72 \mathrm{~h}$, and cell viability was analyzed using MTT assay. (B\&C) MCF10A, MCF-7 and MDA-MB-231 cells were treated with $40 \mu \mathrm{M}$ MAG-DHA alone or in the co-presence of $5 \mathrm{mM}$ NAC for $48 \mathrm{~h}$, and cellular ROS was stained with DCFH-DA and analysed with fluorescent microscopy. (D) MCF10A, MCF-7 and MDA-MB-231 cells were treated with $40 \mu \mathrm{M}$ MAG-DHA alone or in the co-presence of $5 \mathrm{mM} \mathrm{NAC}$ for $48 \mathrm{~h}$, and the content of MDA was determined by MDA kit. (E\&F) MCF-7 and MDA-MB-231 cells were treated with $40 \mu \mathrm{M}$ MAG-DHA alone or in the co-presence of $5 \mathrm{mM} \mathrm{NAC}$, and the protein expression of oxidative stress response marker Nrf2 and HO-1 was monitored by western blotting analysis. Results are presented as the mean \pm SEM from three independent experiments, $* P<0.05$; $* * P<$ 0.01 by Newman-Keuls test. 

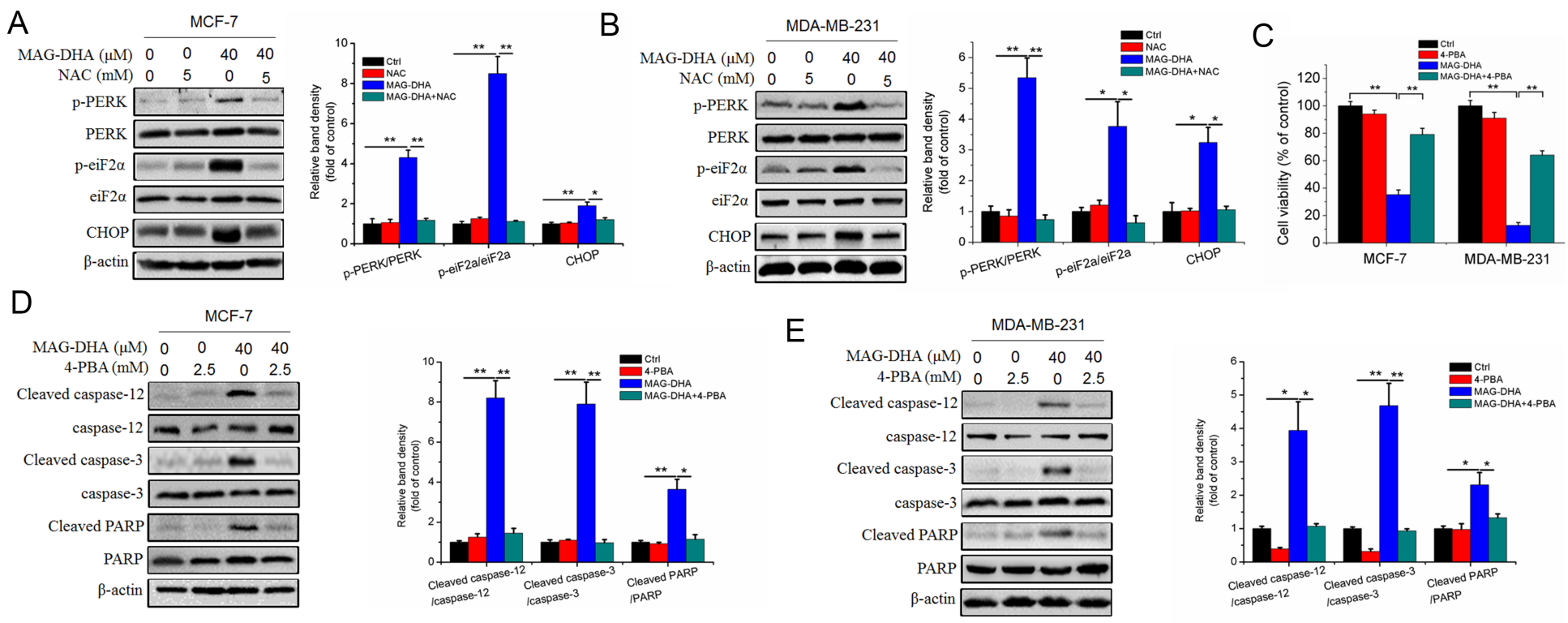

Figure 2

MAG-DHA-mediated lipid peroxidation induced ER stress and cell apoptosis. (A\&B) MCF-7 and MDA-MB231 cells were treated with $40 \mu \mathrm{M}$ MAG-DHA alone or in the co-presence of $5 \mathrm{mM} \mathrm{NAC}$, and the protein expression of the ER stress markers such as p-PERK, PERK, p-eiF2a, eiF2 $a$ and CHOP (G\&H) was monitored by western blotting analysis. (C) MCF-7 and MDA-MB-231 cells were treated with MAG-DHA $(40 \mu \mathrm{M})$ alone or in the co-presence of $2.5 \mathrm{mM}$ 4-PBA (an ER stress inhibitor) for $72 \mathrm{~h}$, and cell viability was analyzed using MTT assay. (D\&E) MCF-7 and MDA-MB-231cells were treated with $40 \mu \mathrm{M}$ MAG-DHA alone or in the co-presence of $2.5 \mathrm{mM}$ 4-PBA, and the protein expression of the apoptotic markers such as cleaved caspase-12, caspase-12, cleaved caspase-3, caspase-3, cleaved PARP and PARP was measured. Results are presented as the mean \pm SEM from three independent experiments, ${ }^{*} P<0.05 ; * \star P<0.01$ by Newman-Keuls test. 

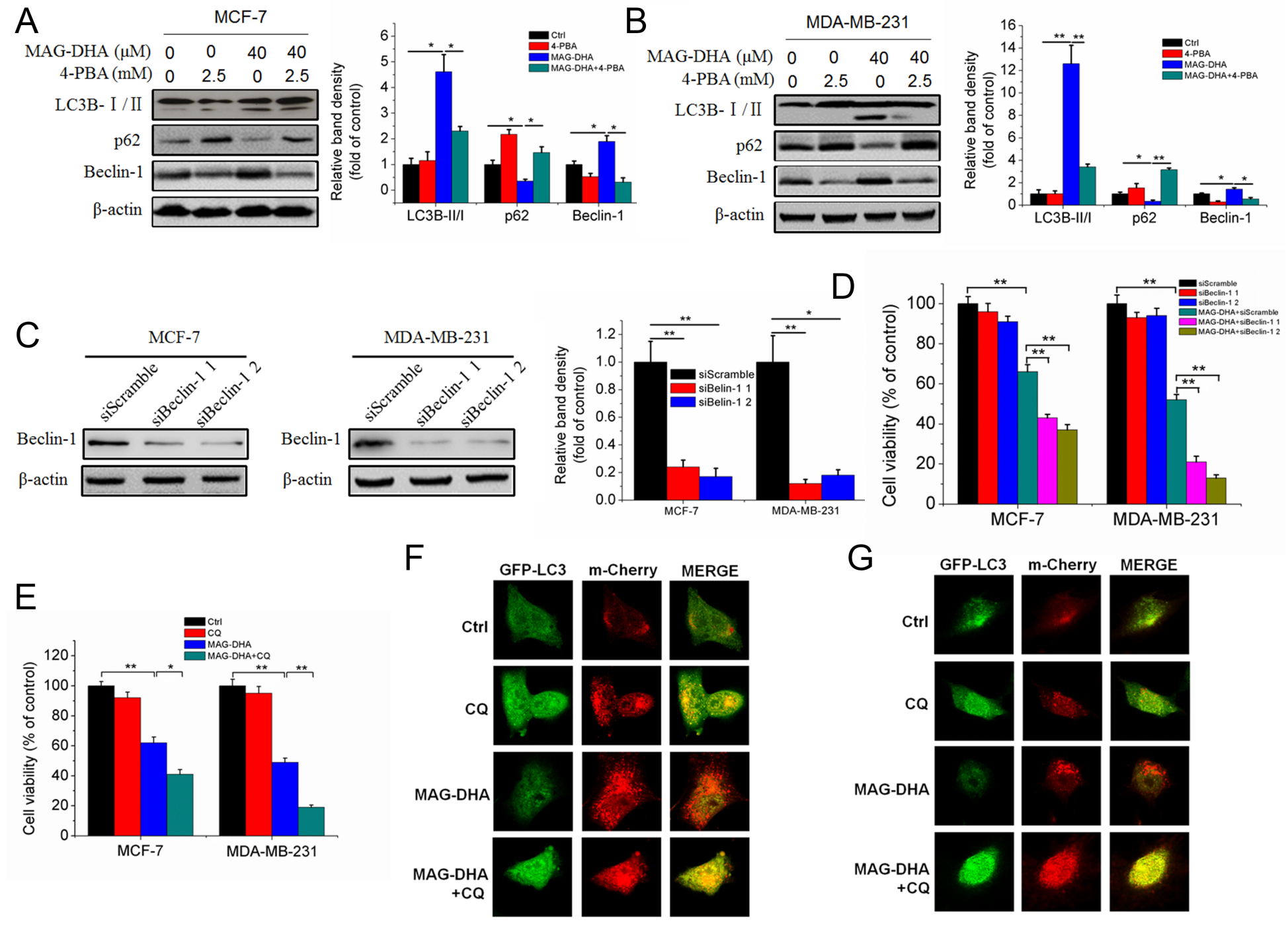

\section{Figure 3}

MAG-DHA-induced ER stress triggered cell autophagy. (A\&B) MCF7 and MDA-MB-231 cells were treated with $40 \mu \mathrm{M}$ MAG-DHA alone or in the co-presence of $2.5 \mathrm{mM}$ 4-PBA, and the protein expression of the autophagic markers such as LC3B囚/囚, p62 and Beclin-1 was monitored by western blotting analysis. (C)Protein expression levels of Beclin-1 after siRNA treatment against Beclin-1 in MCF7 and MDA-MB-231 cells. (D)siScramble and Beclin-1 siRNA-treated MCF7 and MDA-MB-231 cells were treated with MAG-DHA $(40 \mu \mathrm{M})$ for $48 \mathrm{~h}$. and cell viability was analyzed using the MTT assay. (E) MCF7 and MDA-MB-231 cells were treated with MAG-DHA $(40 \mu \mathrm{M})$ alone or in the co-presence of $5 \mu \mathrm{M}$ chloroquine (CQ) for $48 \mathrm{~h}$, and cell viability was analyzed using MTT assay. (F\&G) MCF7 and MDA-MB-231 cells were transfected with an adenovirus of tandemfluorescent mRFP-GFP-LC3B. Cells were treated with MAG-DHA ( $40 \mu \mathrm{M})$ alone or in the co-presence of $5 \mu \mathrm{M}$ chloroquine (CQ) for $48 \mathrm{~h}$, and fluorescence was read by confocal microscope. Results are presented as the mean \pm SEM from three independent experiments, ${ }^{*} P<0.05$; ${ }^{* *} P<0.01$ by Newman-Keuls test. 
A
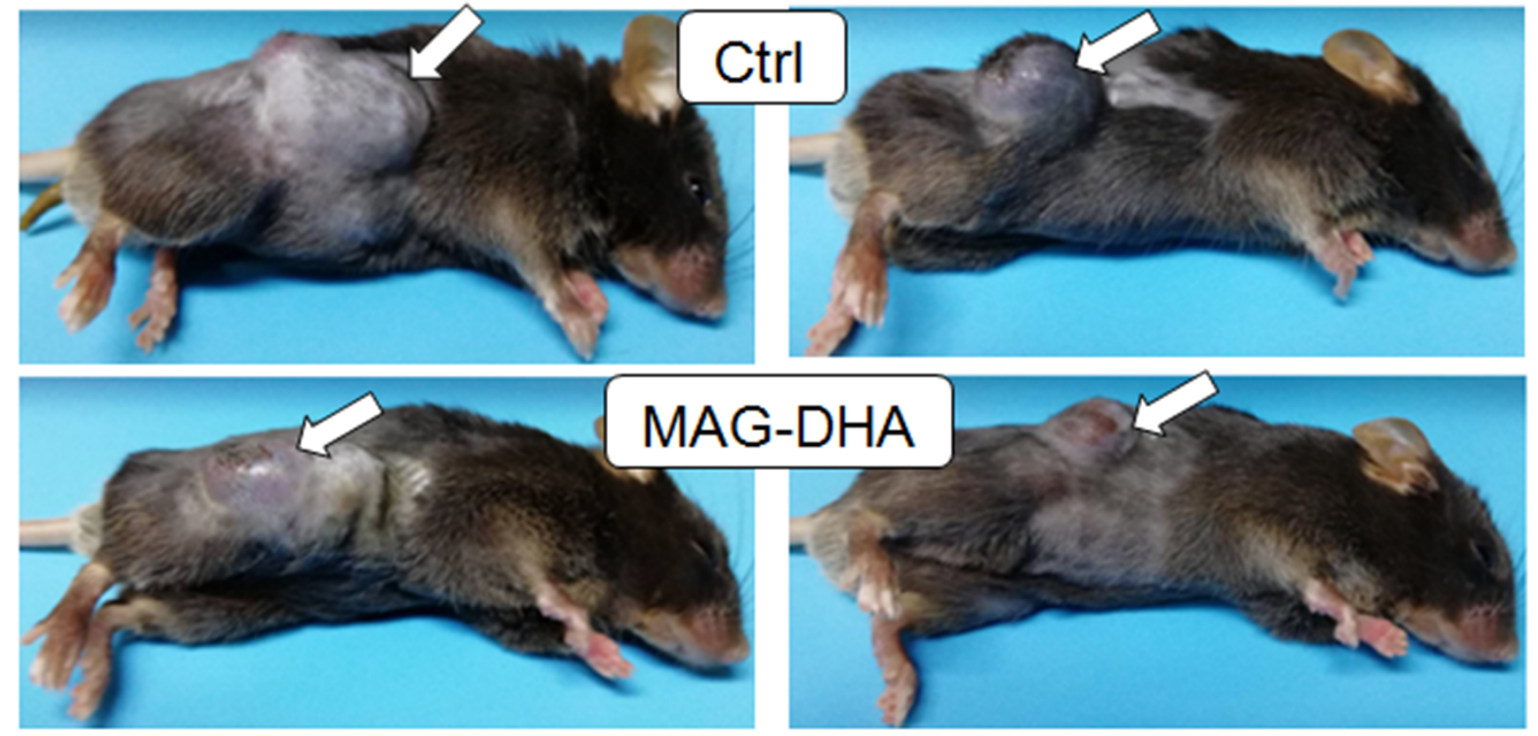

B

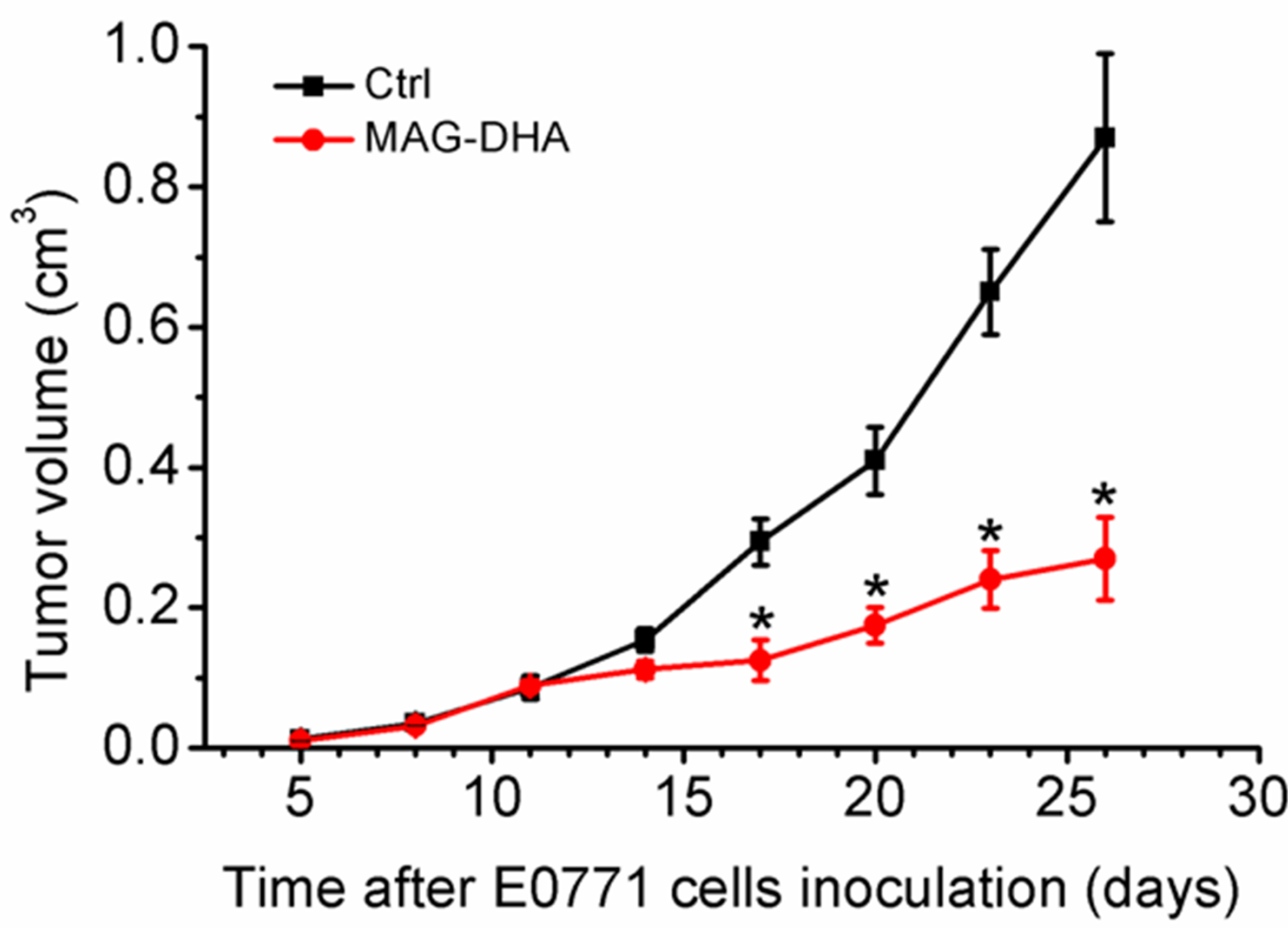

Figure 4

Effects of MAG-DHA on the growth of E0771 cell xenografts. (A) Representative tumor photographs showing tumor formation at 28 days after cell implantation.(B) E0771 cells(2 106 cells/100 $\mu$ lserum-free RPMI 1640) were subcutaneously injected into C57/BL6 mice as described in the Materials and Methods section. Tumor size was measured every 3 days, and tumor volume was calculated on the basis of the following formula: tumor volume $=($ length $\times$ width 2$) \times 0.5$. The points represent mean tumor volume \pm 
SEM obtained from 10 control(Ctrl) mice or 10 MAG-DHA-treated animals. ${ }^{*} \mathrm{P}<0.05 ;{ }^{* \star} \mathrm{P}<0.01$ compared to the corresponding control.
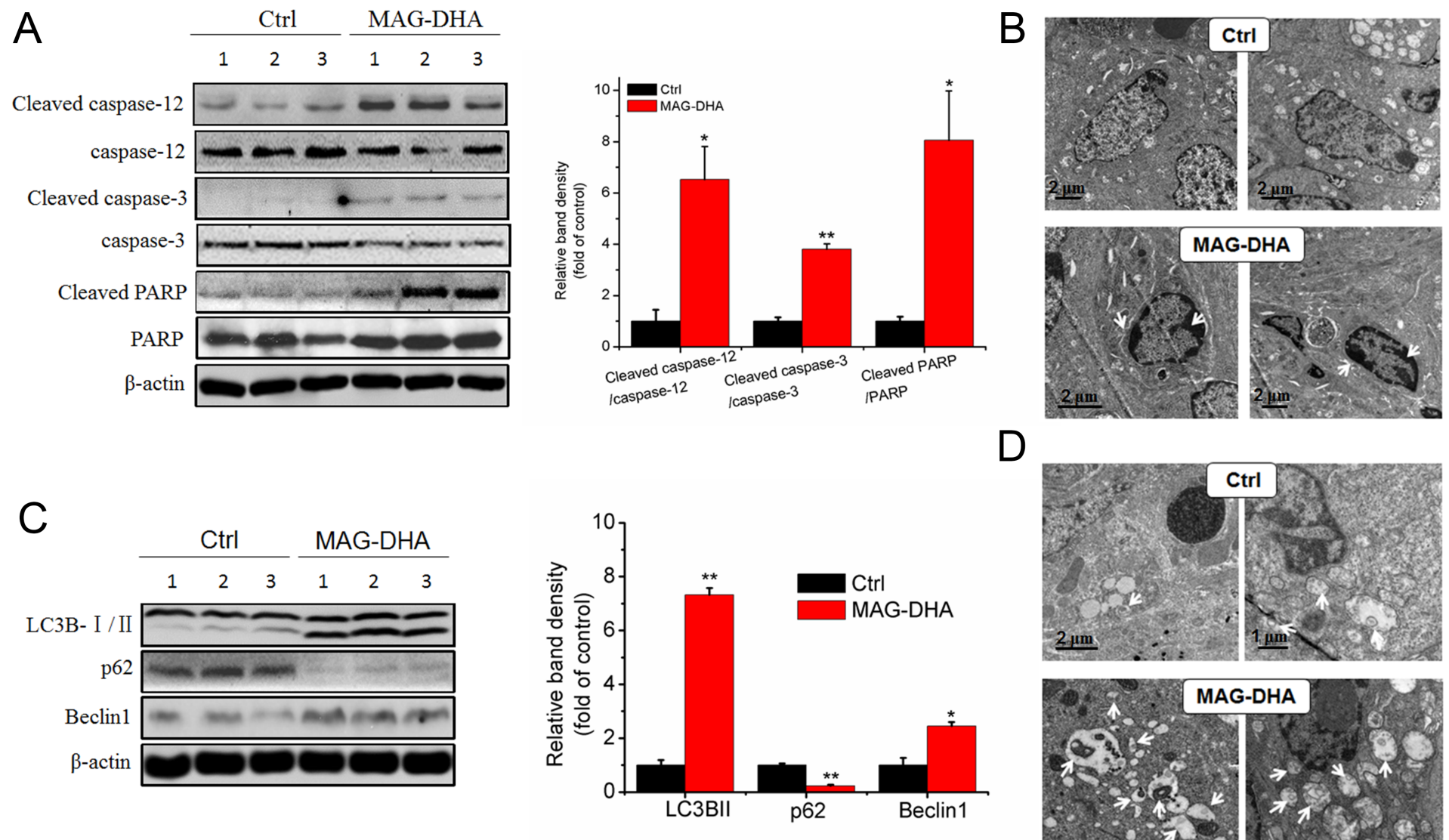

$\mathrm{D}$
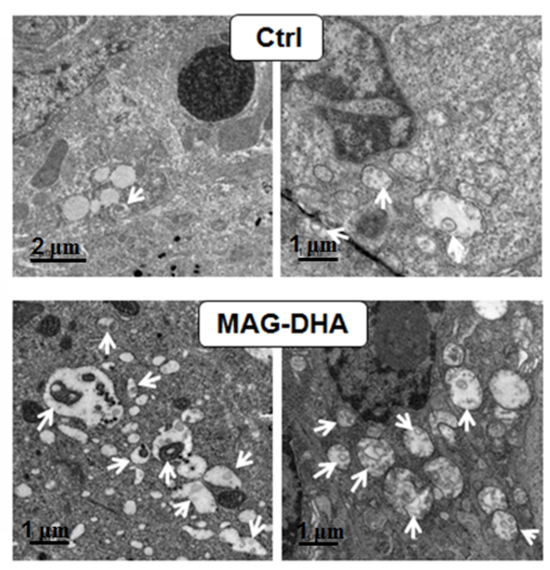

\section{Figure 5}

MAG-DHA intervention induced apoptosis and autophagy in the E0771 cell xenografts. (A) The apoptotic markers such as cleaved caspase-12, caspase-12, cleaved caspase-3, caspase-3, cleaved PARP and PARP were monitored by western blotting analysis in tumor tissues from control and MAG-DHA group. (B) The tumor tissues were fixed and analyzed for apoptosis induction using the transmission electron microscopy (TEM). White arrows indicated chromatin marginalization in E0771 cells from MAG-DHA group.(C) The autophagic markers such as LC3区/囚, p62 and Beclin-1 were monitored by western blotting analysis in tumor tissues from controland MAG-DHA group. (D) The tumor tissues were fixed and analyzed for autophagosome formationusing TEM. White arrows indicated autophagosome formation in E0771 cells from controland MAG-DHA group. 
A

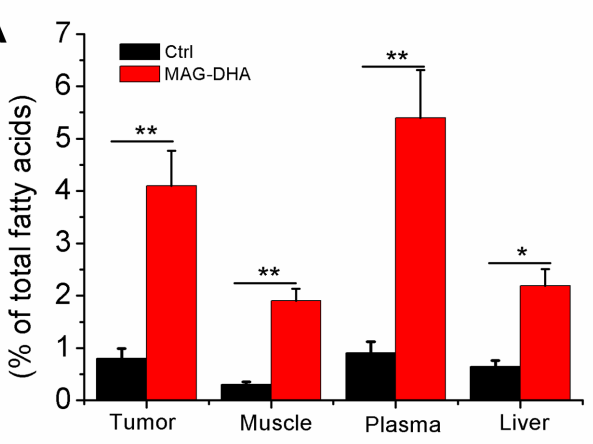

C

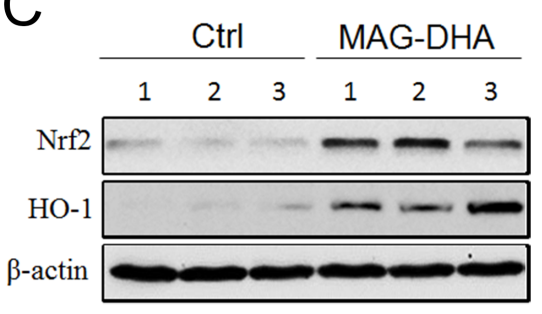

B
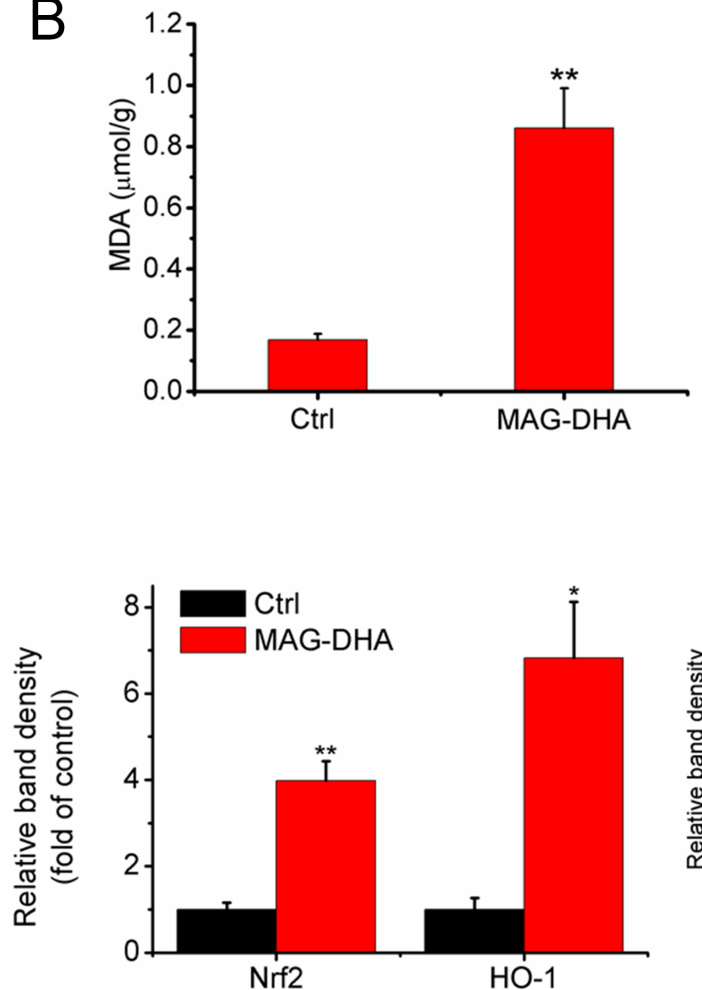
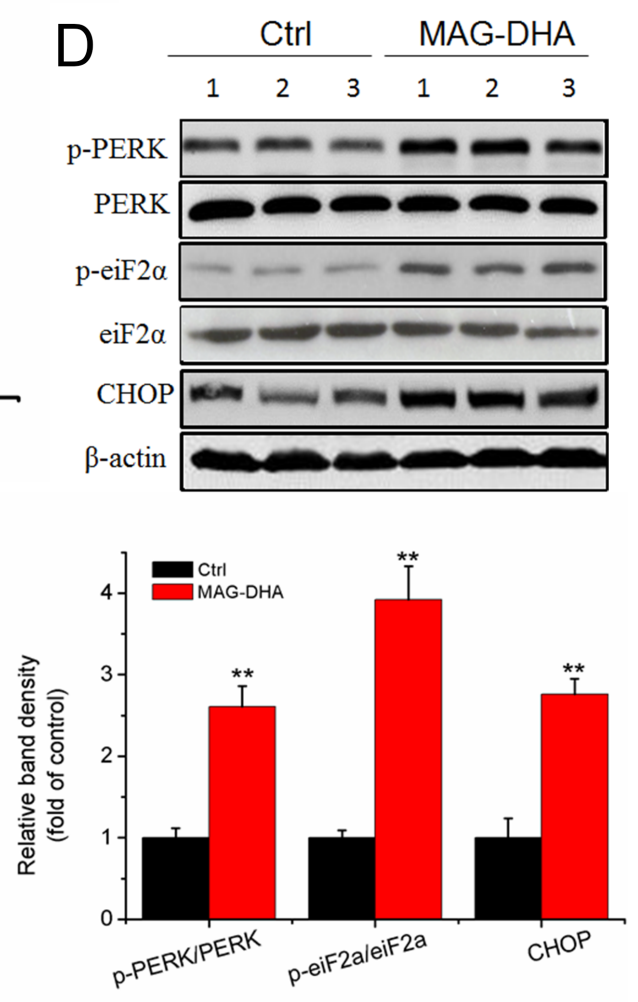

Figure 6

MAG-DHA intervention induced lipid peroxidation, activated anti-oxidative stress response and triggered ER stress in E0771 xenografts. (A) DHA levels in plasma and tissues from control and MAG-DHA group. (B) The content of MDA was measured by MDA kit in tumor tissues from control and MAG-DHA group.

(C) The sensors of oxidative stress Nrf2 and HO-1 were monitored by western blotting analysis in tumor tissues from control and MAG-DHA group. (D) The ER stress markers such as p-PERK, PERK, peiF2a,eiF2aand CHOP were measured by western blotting analysis in tumor tissues from control and MAG-DHA group. Results are presented as the mean \pm SEM from three independent experiments, ${ }^{*} \mathrm{P}<$ 0.05 ; ${ }^{*} \mathrm{P}<0.01$ compared to the corresponding control. 


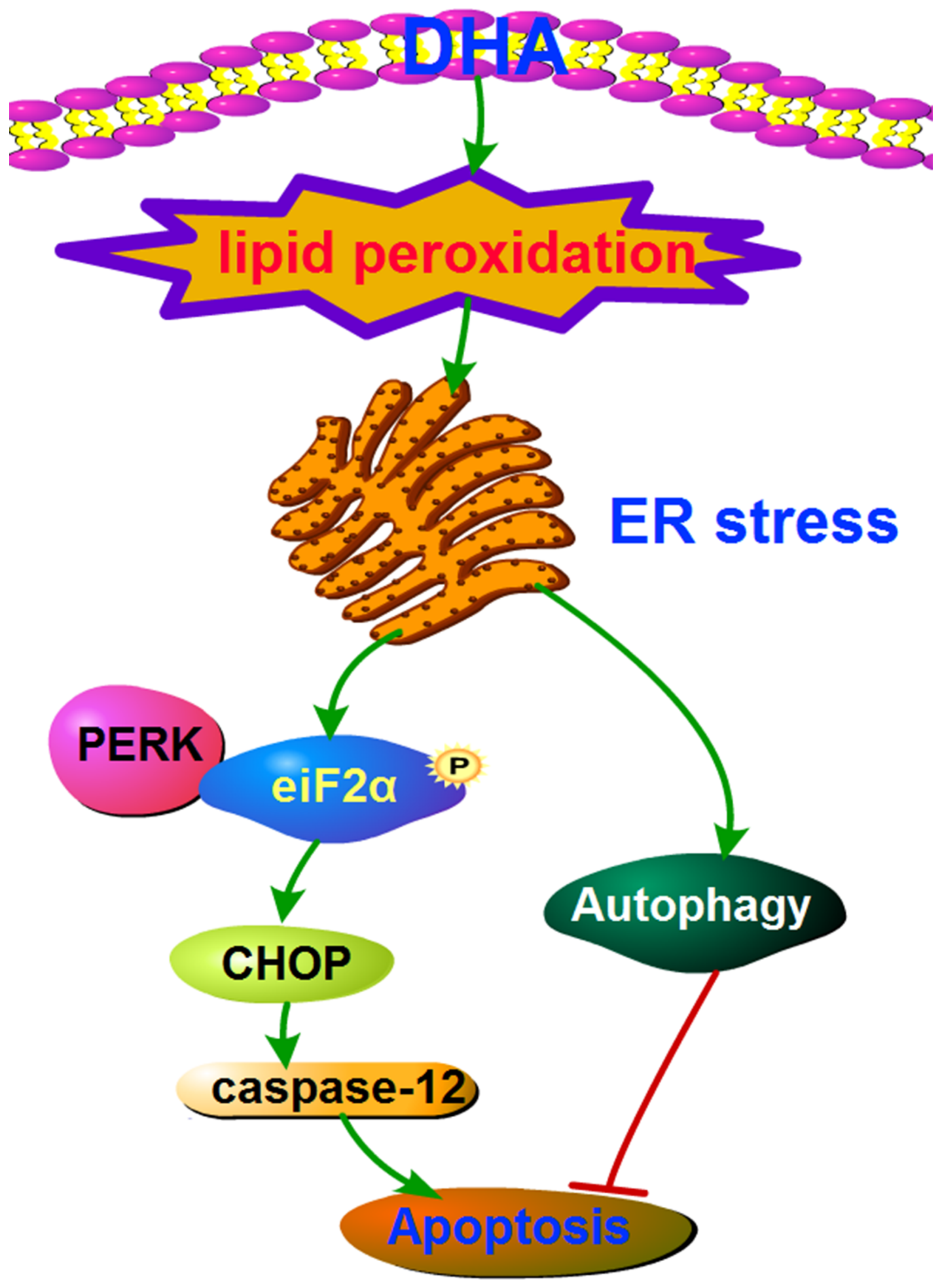

Figure 7

Schematic depicting the anti-cancer mechanism of MAG-DHA on breast cancer. The prevention of MAGDHA againstcultured breast cancer cells or in vivo tumor xenografts was strongly associated with lipid peroxidation-mediated ER stress, which induced cell apoptosis and autophagy. Notably, ER-induced autophagy suppressed MAG-DHA-mediated apoptotic cell death. 


\section{Supplementary Files}

This is a list of supplementary files associated with this preprint. Click to download.

- SupplementaryFigure1.tif

- SupplementaryFigure2.tif

- SupplementaryFigure3.tif 